Session 1526

\title{
Curriculum Development for Rapid Prototyping
}

\author{
Ken Patton and Paul Cheng-Hsin Liu, \\ Saddleback College/ \\ California State University, Los Angeles \\ Project web address: http://www.rptechnician.com
}

\begin{abstract}
This project (NSF ATE DUE 0302314) is in its last year of a three-year project. It was funded July 1, 2001. The focus of the grant is to develop curriculum to train technicians in the use of solid modeling as a "Time Compression" tool to help manufacturers and designers reduce cycle time to market. Curriculum is broken down to modules covering such topics as history, processes, materials, uses, current trends, and applications. Of particular interest is its application to the Entertainment Market (animation), and Architecture. We conducted the first "Train the Trainer" summer workshop at San Diego City College in July 2003. The second workshop will be held in summer 2004 at Saddleback College to conclude this project. Saddleback College, Cal State University, Los Angeles, and San Diego City College have developed this project.
\end{abstract}

\section{Introduction}

The focus of this grant is to develop curriculum to train technicians in the use of solid modeling as a "Time Compression" tool to help manufacturers and designers reduce cycle time to market. As the global marketplace becomes increasingly competitive, products must be produced in shorter and shorter time frames. New time-compression technologies allow product developers to design, prototype, and produce products much more quickly and accurately than could have been imagined even a decade ago. RP systems quickly produce physical models and prototype parts from three-dimensional computer models, such as CAD, CT and MRI scan data. Layer by layer, RP machines fabricate plastic, wood, ceramic, and metal parts using thin, horizontal cross sections from the computer model. With rapid prototyping, the model can often be made within hours, minimizing cycle times and maximizing productivity. The demand for technologists trained in RP has exploded in recent years. Some of the practical applications of RP are visualization, design verification, and even real part fabrication [3]. Figures 1 and 2 show how customers are using RP models and the major RP industry sectors [8].

In southern California there has been a shift from defense driven build-to-specifications contract work to a highly competitive business environment requiring constant development of innovative new products and product variations/improvements. There is more and more design houses moved to Southern California in the last decade than ever. For example, just in the automotive industry alone, there are more than 20 companies established their design facilities from Ventura County, Los Angeles County, Orange County, and down to San Diego County. 
Session 1526

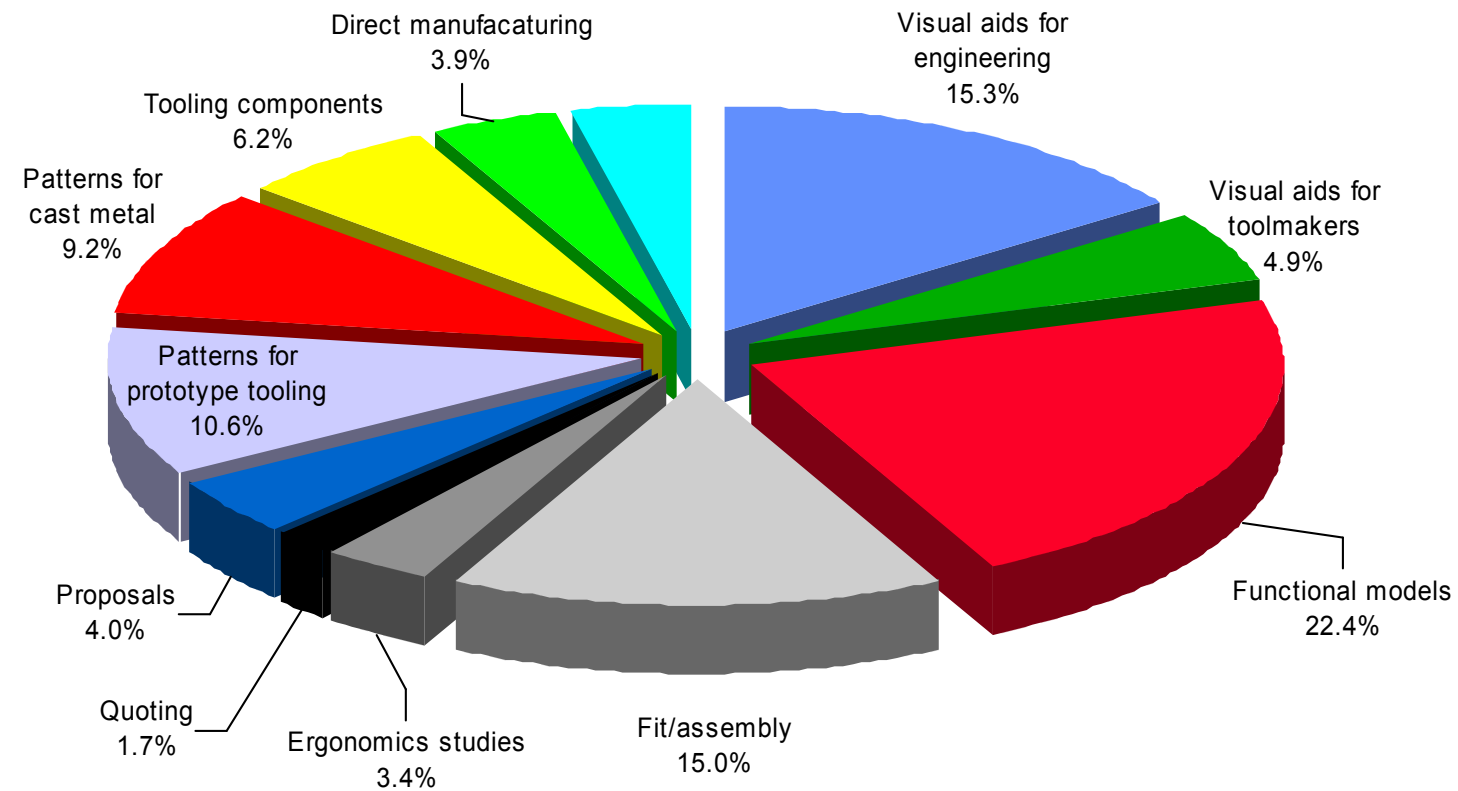

Figure 1. RP applications [8].

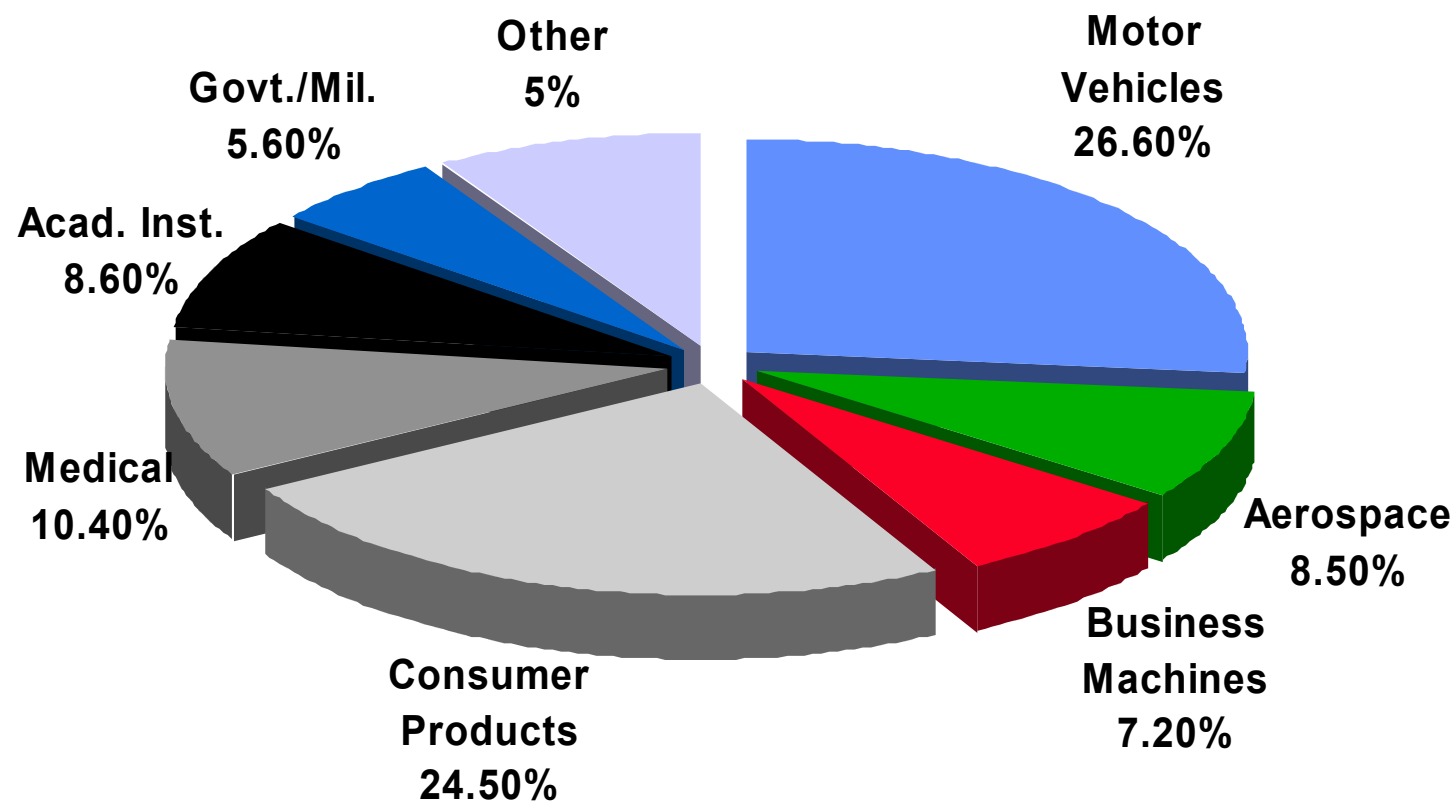

Figure 2. Major RP Industry Sectors [8].

Proceedings of the 2004 American Society for Engineering Education Annual Conference \& Exposition Copyright (O 2004, American Society for Engineering Education 
Product designers have always made models, or prototypes, to demonstrate proof of concept. This process is extremely time consuming and expensive. Rapid Prototyping is the right tool to get the design to manufacture not only applied to the traditional manufacturing and aerospace industries but also to one that people rarely thought about before. The issue has become more challenging in the Hollywood and Disneyland entertainment industries. Traditionally, the entertainment industries rely on many artists to perform the designs to get the ideas to the screens or theme parks. However, since most of the artists do not have any manufacturing background, the designs usually are tested and modified many times before useful models appeared. Recent years, these industries have come to the partnering institutions for technical assistance and training because they have heard about rapid prototyping and their close vicinity to these institutions. Great results turned out due to the help from the expertise in the project team. Recognizing the needs of these non-traditional manufacturing sectors of industries and the Art students who will be employed in these companies, it is necessary to tailor a special set of Rapid Prototyping curriculum to meet their requirements.

A valid process manufacturing plan can greatly shorten time-to-market and therefore acquisition of the funding necessary to go into production. Speeding this product development process even more is the ability to send such design code anywhere in the world via high speed Internet connections. Once a product is proofed and deemed ready for manufacture, the machine code to produce the final object can also be sent anywhere in the world for its actual production. While e-commerce is focused on the buying and selling of products and services, e-production is centered on the actual creation of goods and commodities. The availability of different prototyping systems at each of the three partner schools, all connected via the internet, are giving students first hand experience in how technologies can be utilized to speed product development and production while providing a contextual learning environment which will facilitate the acquisition of relevant skills.

There are three major institutions involved in this project: Saddleback College, San Diego City College, and California State University, Los Angeles. Each school plays an integral part of the project. Through the leadership of the Principal Investigator Ken Patton, the Dean of Business Science, Vocational Education and Economic Development at Saddleback College, the team has developed Rapid Prototyping curriculums, taught RP in full-blown course and RP elements in some design and manufacturing courses, established collaboration with RP industry and end users, conducted student RP projects, and disseminated the results in RP workshop in summer 2003.

\section{Rapid Prototyping Technologist Workshop}

The Rapid Prototyping Technologist "Train the Trainer" Workshop was held during July 27 to August 1, 2003 at San Diego City College. There were twenty-seven participants came from education institutions, including three student assistants. Of the twenty-seven people four were from four-year universities and the remaining twenty-three were from two-year community colleges. There were eleven people representing the hosting organizations, including nine from the project partnering institutions, one from entertainment industry and one from Rapid Prototyping consulting company. And there were nine presenters from Rapid Prototyping industry gave wonderful vendor presentations and vendor showcase. The grand total number of 
participants of this summer workshop was forty-seven. Figure 3 shows the participants by categories.

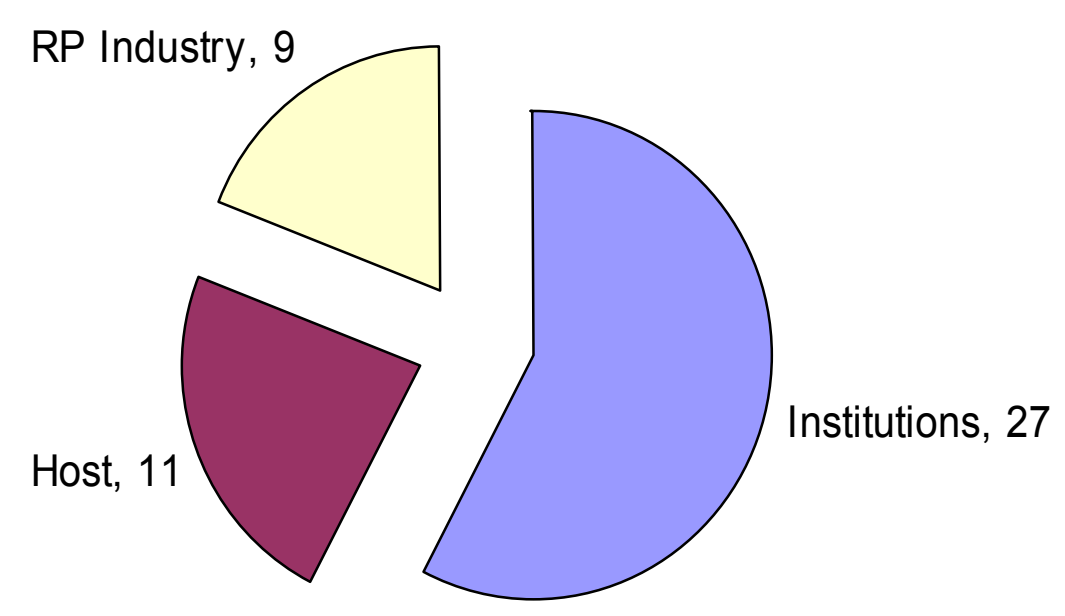

Figure 3. Workshop participants by categories.

The Rapid Prototyping Technologist Summer Workshop officially started on Sunday afternoon with welcome orientation and registration and finished the night with a nice vendor sponsored networking dinner. The Monday morning keynote speech delivered by Terry Wohlers, the guru of Rapid Prototyping, was a major delight for the workshop participants. There were Rapid Prototyping overview, hands-on lab sessions, vendor presentations and demonstrations, and curriculum development populated the rest of the workshop. The main target audience of this workshop was participants from two- and four-year institutions that are either considering or currently using Rapid Prototyping technologies. They were all impressed with the practical hands-on activities in the laboratory and vendors' showcase. There were four Rapid Prototyping technologies present at the workshop: 3D Systems' ThermoJet, Stratasys' Prodigy and Dimension, Z-Corp's Z310, Helisys' Laminated Object Manufacturing (LOM) 2030. Solidworks, the design software, and Materialise, the RP file enhancement software (Magic), also introduced their products in the workshop. Sony demonstrated its capability using the high end RP machine. BJB Enterprises showed how to make rubber silicon mold from RP parts. And the workshop finished with RP curriculum development and implementation and NSF funding opportunities the last day before closing ceremony and evaluation. In general, the workshop was packed with exciting activities and yet not overwhelming materials. There were seven institutions indicated that they will buy at least one of the Rapid Prototyping technologies introduced during the workshop. 
Of the twenty-seven evaluations collected from workshop major audience, Table 1 shows the evaluation results. Majority of the participants strongly agreed that the workshop was very successful, with some variations according to individual's former exposure to Rapid Prototyping technologies. There was one person indicated on question 12 that he did not gain any new information regarding NSF funding opportunities. The fact of the matter is that he just received a half million dollar grant from the NSF and is very familiar with the process.

Table 1. Evaluation Analysis

\begin{tabular}{|l|l|l|l|l|l|}
\hline & $\begin{array}{l}\text { Strongly } \\
\text { Agree }\end{array}$ & Agree & Undecided & Disagree & $\begin{array}{l}\text { Strongly } \\
\text { Disagree }\end{array}$ \\
\hline $\begin{array}{l}\text { 1. Overall, the workshop was a worthwhile, } \\
\text { enjoyable experience. }\end{array}$ & 20 & 7 & 0 & 0 & 0 \\
\hline $\begin{array}{l}\text { 2. The content of this workshop was } \\
\text { appropriate. }\end{array}$ & 17 & 10 & 0 & 0 & 0 \\
\hline 3. The workshop met my expectations. & 15 & 9 & 3 & 0 & 0 \\
\hline 4. I learned new material at this workshop. & 24 & 2 & 1 & 0 & 0 \\
\hline $\begin{array}{l}\text { 5. I plan to transfer this material into the } \\
\text { classroom. }\end{array}$ & 18 & 7 & 2 & 0 & 0 \\
\hline $\begin{array}{l}\text { 6. My experience in the curriculum } \\
\text { development session of the workshop will } \\
\text { help me transfer this material into the } \\
\text { classroom. }\end{array}$ & 14 & 7 & 6 & 0 & 0 \\
\hline $\begin{array}{l}\text { 7. Students will benefit from my experience } \\
\text { in this workshop. }\end{array}$ & 20 & 6 & 1 & 0 & 0 \\
\hline $\begin{array}{l}\text { 8. The Workshop facilitators were } \\
\text { knowledgeable and effective. }\end{array}$ & 22 & 5 & 0 & 0 & 0 \\
\hline $\begin{array}{l}\text { 9. The hands-on experiences were } \\
\text { appropriate. }\end{array}$ & 19 & 6 & 1 & 0 & 1 \\
\hline $\begin{array}{l}\text { 10. The information provided by vendors } \\
\text { was helpful }\end{array}$ & 18 & 8 & 1 & 0 & 0 \\
\hline $\begin{array}{l}\text { 11. I made contacts at this workshop that I } \\
\text { will benefit from in the future. }\end{array}$ & 22 & 5 & 0 & 0 & 0 \\
\hline $\begin{array}{l}\text { 12. I am more aware of grant opportunities at } \\
\text { NSF as a result of this workshop. }\end{array}$ & 15 & 8 & 3 & 1 & 0 \\
\hline
\end{tabular}

Most of the participants thought the length of the workshop each day and total days are just about right with suggestions of format and session modifications. And majority of the attendees appreciated the stipend and paid lodging, but indicated in the evaluation that it better changed to one or the other but not both. Regarding the strengths of the workshop, the feedbacks are:

- Vendor showcase and presentation

- Keynote speech

- Knowledgeable hosts

- NSF grant opportunities

- Networking and social events

Proceedings of the 2004 American Society for Engineering Education Annual Conference \& Exposition Copyright (C) 2004, American Society for Engineering Education 
- Hands-on activities in the RP laboratory

- Exposure to several different RP technologies at the same time

- Exposure to RP post-processing

The areas to be improved include the following:

- Need to include design on the computers (since some participants were new to RP)

- Breakout sessions

- More hands-on sessions

- Less curriculum development

- More attention needed on logistic details

The estimated number of students to be impacted by Rapid Prototyping Workshop ranges from 1,547 to 2,547 in the following academic year. The discrepancy of 1,000 students between the upper and lower ends of the student numbers was because one participant wrote $1,000+$ to be impacted and we have not been able to verify that possibility yet.

\section{Conclusion}

The project partners have learned a lot also from conducting the first summer workshop. The team has started coordination on the second workshop while tying up some loose ends of the project to finish on a high note. The second RP summer workshop will be hosted by Saddleback College located in Mission Viejo, California, during July 25-30, 2004 . Vendors are being contacted and logistics are being prepared. There will be many more exciting events and sessions this year. The key contact of the workshop is Dean Ken Patton and his email is kpatton@saddleback.cc.ca.us.

\section{References}

1. Burns, M. Automated Fabrication: Improving Productivity in Manufacturing. Prentice Hall, 1993.

2. Kai, C. C., Fai, L. K., and Lim, C. S. Rapid Prototyping: Principles and Applications in Manufacturing. $2^{\text {nd }}$ Edition, World Scientific Publishing Company, 2003.

3. Jacobs, Paul F. Rapid Prototyping and Manufacturing: Fundamentals of Stereolithography. Society of Manufacturing Engineers, 1992.

4. Jacobs, Paul F. Stereolithography and Other RP\&M Technologies: From Rapid Prototyping to Rapid Tooling. Society of Manufacturing Engineers, 1996.

5. Pham, Duc Truon, Pham, D. T., and Dimoy, S. Rapid Manufacturing: The Technologies and Applications of Rapid Prototyping and Rapid Tooling. Springer-Verlag New York, 2001.

6. $\quad$ Rapid Prototyping Original Equipment Manufacturers' Update Report. SME, 1997. 
7. Rapid Prototyping Systems: Fast Tract to Product Realization. SME, 1994.

8. Wohlers, Terry. Rapid Prototyping: State of the Industry 2003 Worldwide Progress Report. Society of Manufacturing Engineers, 2003.

9. Wood, L. Rapid Automated Prototyping: An Introduction. Industrial Press, 1993.

\section{Acknowledgement}

The authors wish to acknowledge that this work was supported by an NSF ATE grant (DUE \#: 0302314).

\section{Biography}

Ken W. Patton, who has been Dean of Business Science, Workforce and Economic Development at Saddleback College for almost two years, was the Dean of Workforce \& Economic Development at Glendale Community College prior to his current appointment at Saddleback. He also serves on the board of Directors of the National Coalition of Advanced Technology Centers (NCATC), and a member of the Society of Manufacturing Engineers and the American Society of Engineering Educators. He is responsible for the business/technology/Manufacturing Division of the college including development of new programs and curriculum. Saddleback's modern design and manufacturing laboratories were developed and expanded under his supervision of the NSF-funded Rapid Prototyping project. He has made many ties with various manufacturing sectors to get them involved in the Rapid Prototyping technologies.

Dr. Paul Cheng-Hsin Liu is currently a Professor in the Department of Technology in the College of Engineering, Computer Science, and Technology at the California State University, Los Angeles. He holds a Ph.D. in Industrial Engineering from Auburn University. Dr. Liu has a strong background in Manufacturing Processes, Automation, Statistical Quality Control, Six Sigma, Virtual Reality, and others. He is a member of SME, ASQ, and IEEE. He is Certified Manufacturing Engineer (CMfgE) by SME, and Certified Quality Engineer (CQE) by ASQ. 